OPEN ACCESS

Edited by: Zhi-Ming Shao,

Fudan University, China

Reviewed by: Qi-Jun Wu,

ShengJing Hospital of China Medical

University, China

Birsen Yücel,

Cumhuriyet University, Turkey

${ }^{*}$ Correspondence:

Qiang Wu

wuqiang818@126.com

${ }^{t}$ These authors have contributed equally to this work

Specialty section: This article was submitted to Women's Cancer,

a section of the journal

Frontiers in Oncology

Received: 06 June 2020 Accepted: 12 October 2021 Published: 01 December 2021

Citation:

Li W, Ma G, Deng Y, Chen W, Liu Z, Chen F and Wu Q (2021) Systemic Immune-Inflammation Index Is a Prognostic Factor for Breast Cancer Patients After Curative Resection.

Front. Oncol. 11:570208 doi: 10.3389/fonc.2021.570208

\section{Systemic Immune-Inflammation Index Is a Prognostic Factor for Breast Cancer Patients After Curative Resection}

\author{
Wen $\mathrm{Li}^{1 \dagger}$, Guangzhi Ma ${ }^{1 \dagger}$, Yunfu Deng ${ }^{1,2+}$, Wenjie Chen ${ }^{1,3}$, Zhenkun Liu ${ }^{1}$, \\ Fang Chen ${ }^{4}$ and Qiang $\mathrm{Wu}^{1 *}$
}

${ }^{1}$ Lung Cancer Center \& Institute, West China Hospital, Sichuan University, Chengdu, China, ${ }^{2}$ Cancer Center, West China Hospital, Sichuan University, Chengdu, China, ${ }^{3}$ Department of Thoracic Surgery, The Third Affifiliated Hospital of Kunming Medical University (Yunnan Cancer Hospital, Yunnan Cancer Center), Kunming, China, ${ }^{4}$ Breast Center, West China Hospital, Sichuan University, Chengdu, China

Background: The preoperative systemic immune-inflammation index (SII) is correlated with prognosis in several malignancies. The aim of this study was to investigate the prognosis value of SII in patients with resected breast cancer.

Materials and Methods: A total of 784 breast cancer patients who underwent surgical resection were consecutively investigated. The optimal cutoff value of SIl was evaluated using the receiver operating characteristic $(\mathrm{ROC})$ curve. The collection of SIl with clinicopathological characteristic and prognosis was further evaluated.

Results: The optimal cutoff value for SII in the prediction of survival was 514 according to ROC curve analysis. A high SII was significantly correlated with younger age $(P=0.037)$, PR status $(P<0.001)$, and HER2 status $(P=0.035)$. Univariate analysis revealed that $\mathrm{SII}(P<$ 0.001), T-stage $(P<0.001)$, lymph node involvement post-surgery $(P=0.024)$, and histological grade $(P<0.001)$ were significantly related to DFS, and SII $(P<0.001)$, Tstage $(P=0.003)$, lymph node involvement post-surgery $(P=0.006)$, and histological grade $(P<0.001)$ were significantly associated with OS. In multivariate analysis, a high SII was an independent worse prognostic factor for DFS (HR, 4.530; 95\% Cl, 3.279-6.258; $P<0.001$ ) and $\mathrm{OS}(\mathrm{HR}, 3.825 ; 95 \% \mathrm{Cl}, 2.594-5.640 ; P<0.001)$ in all the enrolled patients. Furthermore, subgroup analysis of molecular subtype revealed that SII was significantly associated with prognosis in all subtypes.

Conclusion: Preoperative SII is a simple and useful prognostic factor for predicting longterm outcomes for breast cancer patients undergoing surgery.

Keywords: breast cancer, SII, inflammation, prognostic factor, survival 


\section{INTRODUCTION}

Breast cancer is one of the most commonly diagnosed malignancies and the leading cause of cancer death in women worldwide (1). Despite developments in radiotherapy, chemotherapy, and targeted therapy, surgery is still the main treatment method for localized breast cancer patients. However, its clinical outcome remains unsatisfactory because an appreciable patient ultimately develops local recurrences or distant metastases after resection (2). Therefore, identifying reliable potential biomarkers for stratifying patients who are likely to have a high risk of recurrence or mortality is crucial to the selection of appropriate treatment strategies (3).

Tumor-promoting inflammation and immune system role in cancer surveillance and elimination are enabling hallmarks for malignant cells $(4,5)$. Systemic inflammatory responses can influence cancer formation and progression at the molecular level, such as DNA damage and cell proliferation (6). Except for tumor cells, immune and inflammatory cells, including neutrophils, platelets, and lymphocytes, contribute to malignant cell invasion in the peripheral blood; hence, tumor cells can survive and reseed in distant organs (7). Several inflammation and immunity-based indicators, including lymphocyte count, neutrophil-lymphocyte ratio (NLR), and platelet-lymphocyte ratio (PLR), have been used in predicting survival outcomes (8-11). Systemic immune-inflammation index (SII), calculated by lymphocyte, neutrophil, and platelet counts, reflects the balance of host inflammatory and immune status and is an established prognostic factor in several malignies (12-14). However, the prognostic value of SII in breast cancer patients remains unclear. In the present study, we aimed to evaluate the prognostic value of SII in patients after curative resection for breast cancer.

\section{PATIENTS AND METHODS}

\section{Patients and Follow-Up}

We retrospectively identified consecutive breast cancer patients who underwent surgery at West China Hospital of Sichuan University from June 2012 to July 2015. Inclusion criteria were as follows: (1) patients received surgery; (2) histologically confirmed breast cancer; and (3) patients with sufficient clinicopathological date and clinical information. Exclusion criteria were (1) ductal carcinoma in situ; (2) patients with metastatic disease before surgery; (3) patients with infections, inflammatory, hematologic, or autoimmune diseases; (4) patients received neoadjuvant chemotherapy before surgery; and (5) male breast cancer patients. Histopathological data and clinical information were obtained.

All the patients were followed up every three months in the first three years after operation, every six months in the next five years, and once a year thereafter. Disease free survival (DFS) was defined as the time from the date of diagnosis to the date of disease relapse/ the last follow-up date. Overall survival (OS) was defined as the interval period from the first diagnosis to the death/final follow- up. The present study was approved by the Research Ethics Committee of West China Hospital of Sichuan University, and a written informed consent was obtained from each participant in accordance with the policies of the committee.

\section{Pathology Methods and Molecular Subtypes}

Estrogen receptor (ER), progesterone receptor (PR), and human epidermal growth factor receptor 2 (HER2) statuses and Ki67 expression were determined by immunohistochemical staining. The cutoff value for positive ER or PR was $\geq 1 \%$ of stained cell, and the cutoff value of high Ki- 67 was $\geq 14 \%$ of immunoreactive tumor cell nuclei. Additionally, a value of 0 or $1+$ was reported as HER2 negative, and 3+ was considered HER2 positive. Fluorescence in situ hybridization was performed when the level of staining was $2+$.

For the molecular subtypes, all the patients were classified as luminal A (ER+ and/or PR+, HER2-, Ki-67 <14), luminal B (ER+ and/or PR+, Ki-67 $\geq 14 \%$ or HER2+/any Ki-67), HER2-enriched (ER-, PR-, HER2+, any Ki-67), or triple-negative (ER-, PR-, HER2-, any Ki-67) breast cancer (TNBC), according to the St. Gallen Expert Consensus in 2013 (15).

\section{Data Collection and Definitions}

A complete preoperative blood cell count was obtained within seven days before surgery. According to previous studies, SII was calculated using the formula SII $=\mathrm{P} \times \mathrm{N} / \mathrm{L}$, where $\mathrm{P}, \mathrm{N}$, and $\mathrm{L}$ represent the absolutely platelet count $\left(10^{9} / \mathrm{L}\right)$, neutrophil count $\left(10^{9} / \mathrm{L}\right)$, and lymphocyte count $\left(10^{9} / \mathrm{L}\right)$, respectively $(16)$.

\section{Determination of the SII Cutoff Value}

We used the receiver operating characteristic (ROC) curve to determine the sensitivity and specificity of SII for 5-year survival, and the Youden index was used in calculating and selecting the optimal cutoff value of SII.

\section{Statistical Analysis}

The associations between SII and clinicopathologic characteristics were analyzed using $X^{2}$-test. The survival curves of DFS and OS were depicted using the Kaplan-Meier method and analyzed using the log-rank test. Univariate and multivariate analyses were performed using the Cox proportional hazards model, and the hazard ratios (HRs) and corresponding $95 \%$ confidence intervals (CIs) of each factor were reported. Statistical analyses were performed using the SPSS (version 23.0) software package (SPSS Inc., Chicago, IL, USA). A two-tailed $P$ value of $<0.05$ was considered statistically significant.

\section{RESULTS}

\section{Characteristics of Patients}

There were 1501 breast cancer patients who were diagnosed with breast cancer in West China Hospital of Sichuan University from June 2012 to July 2015. Among all the 1501 breast patients, 717 were excluded as they not meet the inclusion criteria of the study, 
and then a total of 784 female breast cancer patients who underwent surgery were included in this study (Figure 1). The median age was 49 years (20-89 years), and the median follow-up period was 65.5 months (3-91.5months). Tumor relapse occurred in 157 patients, 108 of which died. A total of 170 (21.7\%) patients were younger than 40 years old, and 450 (57.4\%) patients exhibited positive PR expression. The majority of the patients had positive ER expression (62.6\%), high Ki67 proliferation (63.1\%), and negative HER2 expression (75.0\%). The clinical and pathologic characteristics of all the included patients are shown in Table $\mathbf{1}$.

\section{ROC Analysis for the Prediction of Survival}

The results of ROC analysis showed that the area under the ROC curve (AUC) of SII for predicting DFS and OS were $0.724(P<$ 0.001 ; 95\% CI, 0.679-0.770) and 0.703 ( $P<0.001$; 95\% CI, $0.645-$ 0.761 ), respectively (Figures 2A, B). According to the Youden index, an SII value of 514 was the optimal cutoff value, and sensitivity and specificity were $63.4 \%$ and $75.0 \%$ for OS, respectively. The patients were then stratified into two groups, and $562(71.7 \%)$ patients showed low SII, whereas $222(28.3 \%)$ patients had high SII.

\section{Relationships Between SII and Clinicopathological Characteristics}

As shown in Table 1, SII was significantly related to younger age $(P=0.037)$, positive PR expression $(P<0.001)$, and positive HER2 expression $(P<0.001)$ but not to Ki67 expression level, ER status, $\mathrm{T}$-stage, $\mathrm{N}$-stage, high histological grade, surgery type, chemotherapy, hormonal therapy, target therapy and radiotherapy.

\section{Correlations of the SII With Survival}

The Kaplan-Meier survival curves analysis showed that high SII is a poor prognostic factor for DFS and OS. The 5-year survival rates for DFS and OS in the entire cohort were $79.9 \%$ and $86.2 \%$, respectively. The 5-year DFS rate in the high SII group was significantly shorter than in the low SII group (57.0\% and $84.1 \%$, respectively, $P<0.001$; HR, 4.296; 95\% CI, 2.906-6.350; Figure 3A). Moreover, the corresponding 5-year OS rate for patients in the high SII group (72.4\%) was significantly shorter than those in the low SII group (91.2\%; $P<0.001$; HR, $4.304 ; 95 \%$ CI, 3.125-5.929; Figure 3B).

Univariate Cox regression analysis revealed that SII $(P<$ $0.001)$, T-stage $(P<0.001)$, lymph node involvement post-

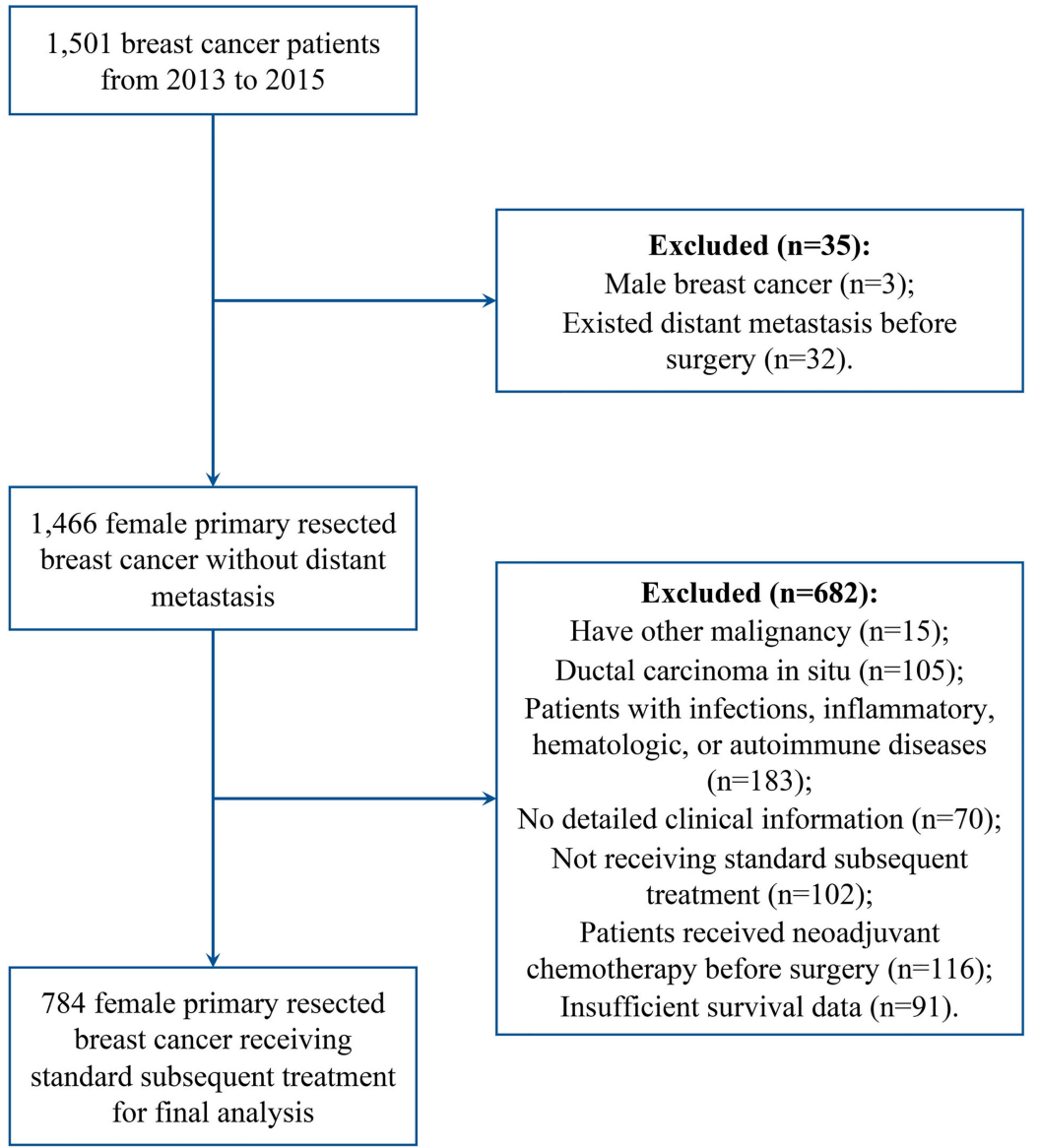

FIGURE 1 | Flow chart of patient selection. 
TABLE 1 | Association of the systemic immune-inflammation index (SII) with the patient and tumor characteristics.

\begin{tabular}{|c|c|c|c|c|}
\hline & Total & Low SII & High SII & $P$ value \\
\hline Age & 784 & 562 & 222 & 0.037 \\
\hline$\leq 40$ & 170 (21.7\%) & $111(19.8 \%)$ & 59 (26.6\%) & \\
\hline$>40$ & $614(78.3 \%)$ & $451(80.2 \%)$ & $163(73.4 \%)$ & \\
\hline ER & & & & 0.416 \\
\hline- & 293 (37.4\%) & 215 (38.3\%) & 78 (35.1\%) & \\
\hline+ & 491 (62.6\%) & 347 (61.7\%) & 144 (64.9\%) & \\
\hline PR & & & & $<0.001$ \\
\hline- & 334 (42.6\%) & 273 (48.6\%) & $61(27.5 \%)$ & \\
\hline+ & 450 (57.4\%) & 289 (51.4\%) & 161 (72.5\%) & \\
\hline HER2 & & & & 0.035 \\
\hline- & 588 (75.0\%) & 433 (77.0\%) & 155 (69.8\%) & \\
\hline+ & 196 (25.0\%) & 129 (23.0\%) & 67 (30.2\%) & \\
\hline Ki-67 status & & & & 0.396 \\
\hline- & 289 (36.9\%) & 202 (35.9\%) & 87 (39.2\%) & \\
\hline+ & 495 (63.1\%) & 360 (64.1\%) & 135 (60.8\%) & \\
\hline pT Stage & & & & 0.949 \\
\hline 1 & 249 (31.8\%) & 178 (31.7\%) & 71 (32.0\%) & \\
\hline 2 & 450 (57.4\%) & $321(57.1 \%)$ & $129(58.1 \%)$ & \\
\hline 3 & $60(7.7 \%)$ & 45 (8.0\%) & $15(6.8 \%)$ & \\
\hline 4 & $25(3.2 \%)$ & $18(3.2 \%)$ & 7 (3.2\%) & \\
\hline pN Stage & & & & 0.377 \\
\hline 0 & 381 (48.6\%) & 283 (50.4\%) & 98 (44.1\%) & \\
\hline 1 & $276(35.2 \%)$ & 188 (33.5\%) & 88 (39.6\%) & \\
\hline 2 & 100 (12.8\%) & 71 (12.6\%) & 29 (13.1\%) & \\
\hline 3 & 27 (3.4\%) & 20 (3.6\%) & $7(3.2 \%)$ & \\
\hline Histological grade & & & & 0.337 \\
\hline$|-| \mid$ & 549 (70.0\%) & 388 (69.0\%) & $161(72.5 \%)$ & \\
\hline III & 235 (30.0\%) & 174 (31.0\%) & $61(27.5 \%)$ & \\
\hline Surgery type & & & & 0.538 \\
\hline Mastectomy & $621(79.2 \%)$ & 442 (78.6\%) & 179 (80.6\%) & \\
\hline BCS & 163 (20.8\%) & 120 (21.4\%) & 43 (19.4\%) & \\
\hline Chemotherapy & & & & 0.369 \\
\hline Yes & 281 (35.8\%) & 196 (34.9\%) & 85 (38.3\%) & \\
\hline No & 503 (64.2\%) & 366 (65.1\%) & 137 (61.7\%) & \\
\hline Radiotherapy & & & & 0.627 \\
\hline Yes & 285 (36.4\%) & 205 (36.5\%) & 80 (36.0\%) & \\
\hline No & 499 (63.6\%) & 357 (63.5\%) & 142 (64.0\%) & \\
\hline Hormonal therapy & & & & 0.054 \\
\hline Yes & $510(65.1 \%)$ & 354 (63.0\%) & 156 (70.3\%) & \\
\hline No & 274 (34.9\%) & 208 (37.0\%) & 66 (29.7\%) & \\
\hline Target therapy & & & & 0.220 \\
\hline Yes & 156 (19.9\%) & 118 (21.0\%) & 38 (17.1\%) & \\
\hline No & 628 (80.1\%) & 444 (79.0\%) & 184 (82.9\%) & \\
\hline
\end{tabular}

PR, progesterone receptor; ER, estrogen receptor; TNBC, triple-negative breast cancer; BCS, breast conserving surgery.

surgery $(P=0.024)$, and histological grade $(P<0.001)$ were significantly related to DFS, and SII $(P<0.001)$, T-stage $(P=$ $0.003)$, lymph node involvement post-surgery $(P=0.006)$, and histological grade $(P<0.001)$ were significantly associated with OS (Tables 2, 3).

Multivariate analysis showed that SII, T-stage, lymph node involvement post-surgery, and histological grade had significant associations with DFS and OS (Tables 2, 3).

Subgroup analysis by subtype of breast cancer was performed. Among the 784 enrolled breast cancer patients, 235 (30.0\%) were classified as luminal A subtype, $368(46.9 \%)$ were luminal B subtype, 108 (13.8\%) were HER2 subtype, and 73 (9.3\%) were TNBC subtype. The results showed that a high SII was significantly associated with poor prognosis in all the four subtypes (Figure 4).

\section{DISCUSSION}

In recent years, inflammation has been demonstrated to be a vital factor in tumor growth, invasion, and metastasis, and the association of inflammation with several malignancies has been revealed (17-20). Many studies have investigated SII in various cancers, including esophageal squamous cell carcinoma, non-small cell lung cancer, hepatocellular carcinoma, and germ-cell tumors (7, 21-23). However, reports on the prognostic significance of SII in breast cancer are rare. In the present study, we assessed the prognostic value of SII in breast cancer patients, and the results showed that SII score obtained before surgery is an independent prognosis factor for breast cancer patients, and a high SII is associated with poor DFS and OS. 
A

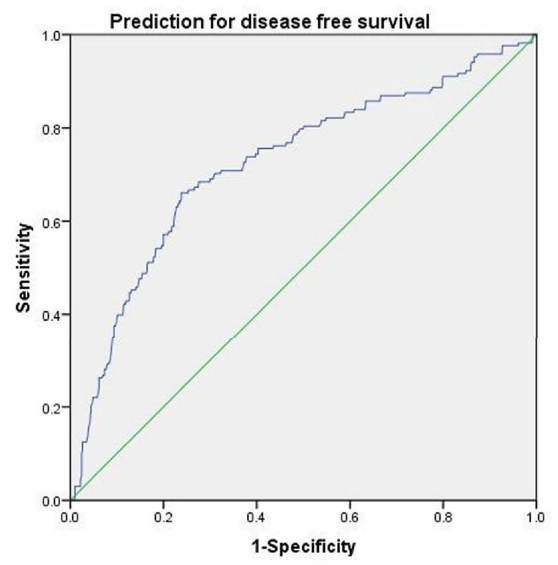

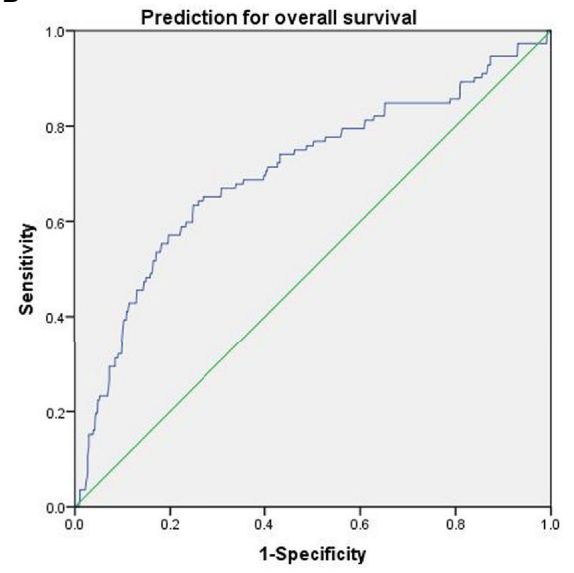

FIGURE 2 | ROC curves of SII for predicting DFS (A) and OS (B).

A

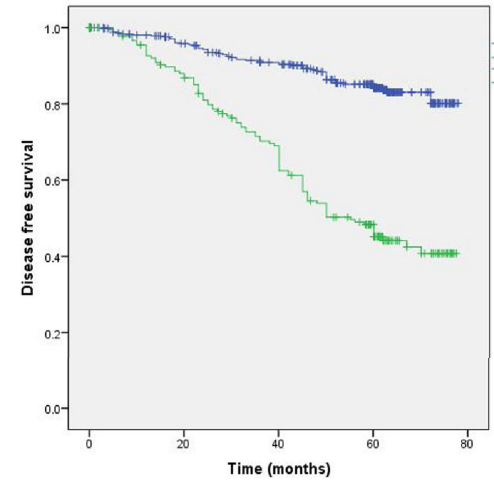

B

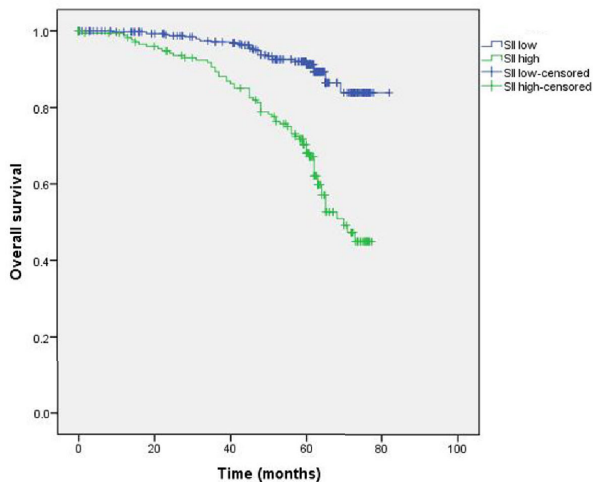

FIGURE 3 | Kaplan-Meier survival analyses of the correlation between SIl and survival among breast cancer patients: DFS (A) and OS (B).

Platelets play vital roles not only in classical hemostatic function but also in creating a hypercoagulable environment that can mediate tumor progression. Specifically, platelets induce tumor growth and promote tumor-associated vasculature development and tumor invasion and metastasis (24). Cancer cells can interact with platelets through cell receptors and signaling molecules, such as the ADP, glycoproteins, P-selectin, and thrombin, and platelets can bind to tumor cells and directly induce tumor growth and metastasis by releasing pro-tumor angiogenic and growth factors once the platelets are activated (25). In the metastatic process of tumor cells, platelets can protect tumor cells from high-velocity forces and immunosurveillance, allowing the establishment of a premetastatic niche. Moreover, platelets can also protect circulating tumor cells from shear stress during cell circulation $(6,26)$. Tumor cells can activate platelets, which in turn secrete transforming growth factor $\beta$ and platelet-derived growth factor and induce tumor cell epithelial-mesenchymal transition (EMT) $(27,28)$. Platelets also increase tumor cell metastatic potential by activating the TGFb-1 and NF-kB pathways, which are responsible for the EMT (29). A high platelet count is associated with increased metastasis and poor outcomes in multiple cancers $(30,31)$.

The immune response of a host to a malignancy is lymphocyte dependent and plays a vital role in tumor defense by inhibiting tumor cell proliferation, invasion, and migration (32). Meanwhile, lymphocytes can release cytokines (such as IFN- $\beta$ and TNF- $\alpha$ ) that are associated with improved prognosis in several cancers (33). By contrast, neutrophils facilitate tumor cell adhesion and the seeding of distant organs by secreting growth factors, including VEGF and proteases (34-38). Some in vitro trials revealed that the cytolytic activities of lymphocytes decrease when co-cultured with neutrophils (39). Calculated from these two parameters, NLR can result in better prediction results than individual factors, and numerous studies demonstrated the prognostic value of NLR in cancer patients (40-42). Robinson et al. in their multicenter cohort study revealed that NLR is associated with the volume of melanoma at presentation and may predict occult sentinel lymph metastases 
TABLE 2 | Results of the analysis of the prognostic factors for disease free survival.

\begin{tabular}{|c|c|c|c|c|c|c|c|c|c|}
\hline & \multicolumn{2}{|c|}{ Univariate analysis } & \multicolumn{2}{|c|}{ Multivariate analysis } & & \multicolumn{2}{|c|}{ Univariate analysis } & \multicolumn{2}{|c|}{ Multivariate analysis } \\
\hline & HR (95\% Cl) & $\begin{array}{c}P \\
\text { value }\end{array}$ & HR $(95 \% \mathrm{Cl})$ & $\begin{array}{c}P \\
\text { value }\end{array}$ & & HR $(95 \% \mathrm{Cl})$ & $\begin{array}{c}P \\
\text { value }\end{array}$ & HR (95\% Cl) & $\begin{array}{c}P \\
\text { value }\end{array}$ \\
\hline SII & & $<0.001$ & & $<0.001$ & SII & & $<0.001$ & & $<0.001$ \\
\hline Low & 1.00 & & 1.00 & & Low & 1.00 & & 1.00 & \\
\hline High & $\begin{array}{c}4.304(3.125 \\
-5.929)\end{array}$ & & $\begin{array}{c}4.530(3.279 \\
-6.258)\end{array}$ & & High & $\begin{array}{c}4.296(2.906 \\
-6.350)\end{array}$ & & $\begin{array}{c}3.825(2.594 \\
-5.640)\end{array}$ & \\
\hline Patient age & & 0.250 & & & Patient age & & 0.745 & & \\
\hline$\leq 40$ & 1.00 & & & & $\leq 40$ & 1.00 & & & \\
\hline$>40$ & $\begin{array}{c}0.807(0.560 \\
-1.163)\end{array}$ & & & & $>40$ & $\begin{array}{c}0.927(0.589 \\
-1.460)\end{array}$ & & & \\
\hline ER & & 0.824 & & & ER & & 0.187 & & \\
\hline- & 1.00 & & & & - & 1.00 & & & \\
\hline+ & $\begin{array}{c}0.964(0.699 \\
-1.330)\end{array}$ & & & & + & $\begin{array}{c}0.774(0.528 \\
-1.133)\end{array}$ & & & \\
\hline PR & & 0.732 & & & PR & & 0.517 & & \\
\hline- & 1.00 & & & & - & 1.00 & & & \\
\hline+ & $\begin{array}{c}0.947(0.692 \\
-1.295)\end{array}$ & & & & + & $\begin{array}{c}0.883(0.605 \\
-1.288)\end{array}$ & & & \\
\hline HER2 & & 0.363 & & & HER2 & & 0.733 & & \\
\hline- & 1.00 & & & & - & 1.00 & & & \\
\hline+ & $\begin{array}{c}0.820(0.535 \\
-1.257)\end{array}$ & & & & + & $\begin{array}{c}0.916(0.552 \\
-1.519)\end{array}$ & & & \\
\hline Ki-67 status & & 0.058 & & & $\mathrm{Ki}-67$ status & & 0.112 & & \\
\hline- & 1.00 & & & & - & 1.00 & & & \\
\hline+ & $\begin{array}{c}1.596(0.983 \\
-2.590)\end{array}$ & & & & + & $\begin{array}{c}1.636(0.892 \\
-3.000)\end{array}$ & & & \\
\hline pT Stage & & $<0.001$ & & $<0.001$ & pT Stage & & 0.003 & & $<0.001$ \\
\hline 1 & 1.00 & & 1.00 & & 1 & 1.00 & & 1.00 & \\
\hline $2-4$ & $\begin{array}{c}1.340(1.163 \\
-1.543)\end{array}$ & & $\begin{array}{c}1.368(1.192 \\
-1.571)\end{array}$ & & $2-4$ & $\begin{array}{c}1.300(1.093 \\
-1.546)\end{array}$ & & $\begin{array}{c}1.377(1.162 \\
-1.632)\end{array}$ & \\
\hline pN Stage & & 0.024 & & 0.027 & pN Stage & & 0.006 & & 0.035 \\
\hline- & 1.00 & & 1.00 & & - & 1.00 & & 1.00 & \\
\hline+ & $\begin{array}{c}1.182(1.022 \\
-1.368)\end{array}$ & & $\begin{array}{c}1.179(1.019 \\
-1.364)\end{array}$ & & + & $\begin{array}{c}1.272(1.070 \\
-1.512)\end{array}$ & & $\begin{array}{c}1.211(1.014 \\
-1.447)\end{array}$ & \\
\hline $\begin{array}{l}\text { Histological } \\
\text { grade }\end{array}$ & & $<0.001$ & & 0.034 & $\begin{array}{l}\text { Histological } \\
\text { grade }\end{array}$ & & $<0.001$ & & 0.006 \\
\hline$|-| \mid$ & 1.00 & & 1.00 & & $|-| \mid$ & 1.00 & & 1.00 & \\
\hline III & $\begin{array}{c}1.795(1.277- \\
2.521)\end{array}$ & & $\begin{array}{c}1.595(1.036 \\
-2.451)\end{array}$ & & \|\| & $\begin{array}{c}2.058(1.364- \\
3.101)\end{array}$ & & $\begin{array}{c}1.937(1.207 \\
-3.106)\end{array}$ & \\
\hline Surgery type & & 0.344 & & & Surgery type & & 0.569 & & \\
\hline Mastectomy & 1.00 & & & & Mastectomy & 1.00 & & & \\
\hline BCS & $\begin{array}{c}1.207(0.821- \\
1.769)\end{array}$ & & & & $\mathrm{BCS}$ & $\begin{array}{c}1.147(0.721- \\
1.820)\end{array}$ & & & \\
\hline Chemotherapy & & 0.08 & & & Chemotherapy & & 0.151 & & \\
\hline No & 1.00 & & & & Yes & 1.00 & & & \\
\hline Yes & $\begin{array}{c}1.340(0.968- \\
1.852)\end{array}$ & & & & No & $\begin{array}{c}0.752(0.508- \\
1.109)\end{array}$ & & & \\
\hline Radiotherapy & & 0.121 & & & Radiotherapy & & 0.533 & & \\
\hline No & 1.00 & & & & Yes & 1.00 & & & \\
\hline Yes & $\begin{array}{c}0.775(0.561- \\
1.068)\end{array}$ & & & & No & $\begin{array}{c}0.885(0.598- \\
1.305)\end{array}$ & & & \\
\hline $\begin{array}{l}\text { Hormonal } \\
\text { therapy }\end{array}$ & & 0.110 & & & $\begin{array}{l}\text { Hormonal } \\
\text { therapy }\end{array}$ & & 0.212 & & \\
\hline No & 1.00 & & & & No & 1.00 & & & \\
\hline Yes & $\begin{array}{c}0.767(0.553- \\
1.060)\end{array}$ & & & & Yes & $\begin{array}{c}0.779(0.525- \\
1.153)\end{array}$ & & & \\
\hline Target therapy & & 0.253 & & & Target therapy & & 0.405 & & \\
\hline No & 1.00 & & & & No & 1.00 & & & \\
\hline Yes & $\begin{array}{c}1.259(0.851- \\
1.858)\end{array}$ & & & & Yes & $\begin{array}{c}1.223(0.764- \\
1.959)\end{array}$ & & & \\
\hline
\end{tabular}

TABLE 3 | Results of the analysis of the prognostic factors for overall survival. 


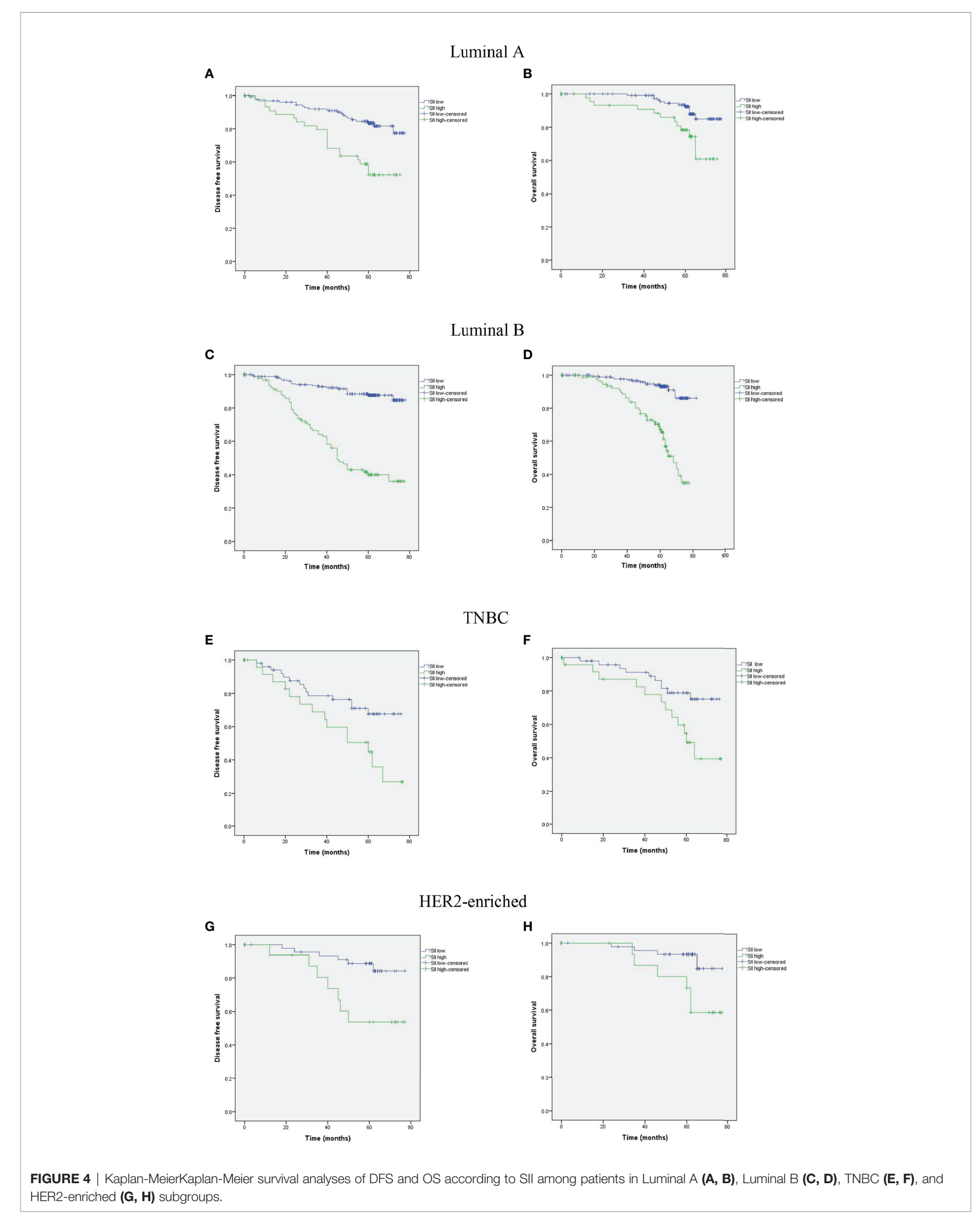


(43). In addition, a meta-analysis showed that a raised baseline NLR is related to nearly twice the risk of recurrence in melanoma (44).

Given the significance of platelets, neutrophils, and lymphocytes in prognosis prediction in cancer patients, an elevated preoperative SII usually indicates elevated inflammatory status and weak immune response. $\mathrm{Li}$ et al. found that preoperative SII is a prognostic indicator for intrahepatic cholangiocarcinoma and patients with increased SII level are associated with poor OS and early tumor recurrence (45). Wang et al. found the role of SII in non-small cell lung cancer patients in a meta-analysis (46). Preoperative elevated SII can be an independent prognostic factor for bladder cancer patients who underwent radical cystectomy (47). Besides, a relevant study also indicated that the DFS and OS time in patients with low SII would have survival longer than those patients with high SII in patients with breast cancer undergoing neoadjuvant chemotherapy, which is consistent with our results (48). Moreover, a meta-analysis involving 2642 patients suggest that an elevated SII predicts poor survival outcomes and is associated with clinicopathological features that indicate tumor progression of breast cancer (49).

SII is calculated based on standard laboratory tests on total platelet, neutrophil, and lymphocyte counts, and all these parameters are routinely measured in the clinical setting. Thus, SII might be a potential marker for tumor recurrence surveillance in breast cancer patients undergoing potentially curative resection; moreover, we hope that the SII may be used in combination with other biomarkers and serve a useful index for evaluating the risk of breast cancer to identify subgroups of patients with poor prognosis and offer therapeutic strategies for breast cancer patients.

This study has several limitations. Firstly, our study is a retrospective study and all the samples were enrolled at a single center. Secondly, with the subgroup analysis, the numbers of patients are less and may influence the outcomes.

\section{REFERENCES}

1. Siegel RL, Miller KD, Jemal A. Cancer Statistics, 2020. CA: Cancer J Clin (2020) 70:7-30. doi: 10.3322/caac.21590

2. Curigliano G, Burstein HJ, Winer PE, Gnant M, Dubsky P, Loibl S, et al. DeEscalating and Escalating Treatments for Early-Stage Breast Cancer: The St. Gallen International Expert Consensus Conference on the Primary Therapy of Early Breast Cancer 2017. Ann Oncol (2017) 28:1700-12. doi: 10.1093/annonc/mdx308

3. Hanahan D, Weinberg RA. Hallmarks of Cancer: The Next Generation. Cell (2011) 144:646-74. doi: 10.1016/j.cell.2011.02.013

4. Beyer K, Baukloh AK, Stoyanova A, Kamphues C, Sattler A, Kotsch K, et al. Interactions of Tumor Necrosis Factor-Related Apoptosis-Inducing Ligand (TRAIL) With the Immune System: Implications for Inflammation and Cancer. Cancers (2019) 11:1161. doi: 10.3390/cancers11081161

5. Berraondo P, Minute L, Ajona D, Corrales L, Melero I, Pio R, et al. Innate Immune Mediators in Cancer: Between Defense and Resistance. Immunol Rev (2016) 274:290-306. doi: 10.1111/imr.12464

6. Stoiber D, Assinger A. Platelet-Leukocyte Interplay in Cancer Development and Progression. Cells (2020) 9:855. doi: 10.3390/cells9040855

7. Hu B, Yang XR, Xu Y, Sun YF, Sun C, Guo W, et al. Systemic ImmuneInflammation Index Predicts Prognosis of Patients After Curative Resection for Hepatocellular Carcinoma. Clin Cancer Res (2014) 20:6212-22. doi: 10.1158/1078-0432.Ccr-14-0442

8. Huszno J, Kolosza Z, Mrochem-Kwarciak J, Rutkowski T, Skladowski K. The Role of Neutrophil-Lymphocyte Ratio, Platelet-Lymphocyte Ratio, and
Thirdly, although SII is an independent predictor, the SII is a nonspecific tumor marker, indicating that further prospective randomized controlled trials are needed to validate our findings.

\section{CONCLUSION}

Our study suggests that SII is a simple and useful prognostic factor for predicting long-term outcomes for resected breast cancer patients, and a high SII suggests poor prognosis.

\section{DATA AVAILABILITY STATEMENT}

The original contributions presented in the study are included in the article/supplementary material. Further inquiries can be directed to the corresponding author.

\section{ETHICS STATEMENT}

The present study was approved by the Research Ethics Committee of West China Hospital of Sichuan University, and a written informed consent was obtained from each participant in accordance with the policies of the committee.

\section{AUTHOR CONTRIBUTIONS}

Data curation: WL, GM, and YD. Investigation: GM and QW. Methodology: YD, WL, and GM. Project administration: QW. Resources: QW. Software: ZL and FC. Visualization: YD. Writing original draft: WL. Writing - review \& editing: QW. All authors contributed to the article and approved the submitted version.

Platelets in the Prognosis of Metastatic Renal Cell Carcinoma. Oncology (2019) 97:7-17. doi: 10.1159/000498943

9. Huszno J, Kolosza Z. Prognostic Value of the Neutrophil-Lymphocyte, Platelet-Lymphocyte and Monocyte-Lymphocyte Ratio in Breast Cancer Patients. Oncol Lett (2019) 18:6275-83. doi: 10.3892/ol.2019.10966

10. Hirahara T, Arigami T, Yanagita S, Matsushita D, Uchikado Y, Kita Y, et al. Combined Neutrophil-Lymphocyte Ratio and Platelet-Lymphocyte Ratio Predicts Chemotherapy Response and Prognosis in Patients With Advanced Gastric Cancer. BMC Cancer (2019) 19:672. doi: 10.1186/s12885-019-5903-y

11. Cantiello F, Russo GI, Vartolomei MD, Farhan ARA, Terracciano D, Musi G, et al. Systemic Inflammatory Markers and Oncologic Outcomes in Patients With High-Risk Non-Muscle-Invasive Urothelial Bladder Cancer. Eur Urol Oncol (2018) 1:403-10. doi: 10.1016/j.euo.2018.06.006

12. Ozkan EE, Kaymak Cerkesli ZA, Erdoğan M. Predictive Value of ImmuneInflammation Indices in Terms of Metabolic Response and Outcome After Curative Radiotherapy for non-Small Cell Lung Cancer. Clin Respir J (2020) 14:849-56. doi: 10.1111/crj.13217

13. Yatabe S, Eto K, Haruki K, Shiba H, Kosuge M, Ohkuma M, et al. Signification of Systemic Immune-Inflammation Index for Prediction of Prognosis After Resecting in Patients With Colorectal Cancer. Int J Colorectal Dis (2020) 35:1549-55. doi: 10.1007/s00384-020-03615-w

14. Ozbek E, Besiroglu H, Ozer K, Horsanali MO, Gorgel SN. Systemic Immune Inflammation Index Is a Promising Non-Invasive Marker for the Prognosis of the Patients With Localized Renal Cell Carcinoma. Int Urol Nephrol (2020) 52:1455-63. doi: 10.1007/s11255-020-02440-y 
15. Goldhirsch A, Winer EP, Coates AS, Gelber RD, Piccart-Gebhart M, Thürlimann B, et al. Personalizing the Treatment of Women With Early Breast Cancer: Highlights of the St Gallen International Expert Consensus on the Primary Therapy of Early Breast Cancer 2013. Ann Oncol (2013) 24:220623. doi: 10.1093/annonc/mdt303

16. Zhu Z, Cong X, Li R, Yin X, Li C, Xue Y, et al. Preoperative Systemic Immune-Inflammation Index (SII) for Predicting the Survival of Patients With Stage I-III Gastric Cancer With a Signet-Ring Cell (SRC) Component. BioMed Res Int (2020) 2020:5038217. doi: 10.1155/2020/ 5038217

17. Kobayashi S, Karube Y, Matsumura Y, Nishihira M, Inoue T, Araki O, et al. Inflammatory Risk Factors for Early Recurrence of Non-Small Cell Lung Cancer Within One Year Following Curative Resection. World J Surg (2020) 44:3510-21. doi: 10.1007/s00268-020-05612-0

18. Szudy-Szczyrek A, Mlak R, Mielnik M, Szczyrek M, Nowaczyńska A, HomaMlak I, et al. Prognostic Value of Pretreatment Neutrophil-to-Lymphocyte and Platelet-to-Lymphocyte Ratios in Multiple Myeloma Patients Treated With Thalidomide-Based Regimen. Ann Hematol (2020) 99:2881-91. doi: 10.1007/s00277-020-04092-5

19. Watts EL, Perez-Cornago A, Kothari J, Allen NE, Travis RC, Key TJ. Haematological Markers and Prostate Cancer Risk: A Prospective Analysis in UK Biobank. Cancer Epidemiol Biomarkers Prev (2020) 29:1615-26. doi: 10.1158/1055-9965.Epi-19-1525

20. Yu JI, Park HC, Yoo GS, Paik SW, Choi MS, Kim HS, et al. Clinical Significance of Systemic Inflammation Markers in Newly Diagnosed, Previously Untreated Hepatocellular Carcinoma. Cancers (2020) 12:1300. doi: $10.3390 /$ cancers 12051300

21. Chovanec M, Cierna Z, Miskovska V, Machalekova K, Kalavska K, Rejlekova $\mathrm{K}$, et al. Systemic Immune-Inflammation Index in Germ-Cell Tumours. $\mathrm{Br} \mathrm{J}$ Cancer (2018) 118:831-8. doi: 10.1038/bjc.2017.460

22. Tong YS, Tan J, Zhou XL, Song YQ, Song YJ. Systemic Immune-Inflammation Index Predicting Chemoradiation Resistance and Poor Outcome in Patients With Stage III Non-Small Cell Lung Cancer. J Trans Med (2017) 15:221. doi: 10.1186/s12967-017-1326-1

23. Wang L, Wang C, Wang J, Huang X, Cheng Y. A Novel Systemic ImmuneInflammation Index Predicts Survival and Quality of Life of Patients After Curative Resection for Esophageal Squamous Cell Carcinoma. J Cancer Res Clin Oncol (2017) 143:2077-86. doi: 10.1007/s00432-017-2451-1

24. Augustine T,N. The Aegis: Platelets as Biomarkers of Tumor Progression. Biomarkers Med (2020) 14:573-85. doi: 10.2217/bmm-2019-0514

25. Meikle CK, Kelly CA, Garg P, Wuescher LM, Ali RA, Worth RG, et al. Cancer and Thrombosis: The Platelet Perspective. Front Cell Dev Biol (2016) 4:147. doi: $10.3389 /$ fcell.2016.00147

26. Gkolfinopoulos S, Jones RL, Constantinidou A. The Emerging Role of Platelets in the Formation of the Micrometastatic Niche: Current Evidence and Future Perspectives. Front Oncol (2020) 10:374. doi: 10.3389/ fonc. 2020.00374

27. Gaertner F, Massberg S. Patrolling the Vascular Borders: Platelets in Immunity to Infection and Cancer. Nat Rev Immunol (2019) 19:747-60. doi: 10.1038/s41577-019-0202-z

28. Mege D, Aubert M, Lacroix R, Dignat-George F, Panicot-Dubois L, Dubois C, et al. Involvement of Platelets in Cancers. Semin Thromb Hemostasis (2019) 45:569-75. doi: 10.1055/s-0039-1693475

29. Labelle M, Begum S, Hynes RO. Direct Signaling Between Platelets and Cancer Cells Induces an Epithelial-Mesenchymal-Like Transition and Promotes Metastasis. Cancer Cell (2011) 20:576-90. doi: 10.1016/ j.ccr.2011.09.009

30. Shoultz-Henley S, Garden AS, Mohamed AS, Sheu T, Kroll MH, Rosenthal DI, et al. Prognostic Value of Pretherapy Platelet Elevation in Oropharyngeal Cancer Patients Treated With Chemoradiation. Int J Cancer (2016) 138:12907. doi: $10.1002 /$ ijc. 29870

31. Ye J, Liao B, Jiang X, Dong Z, Hu S, Liu Y, et al. Prognosis Value of Platelet Counts, Albumin and Neutrophil-Lymphocyte Ratio of Locoregional Recurrence in Patients With Operable Head and Neck Squamous Cell Carcinoma. Cancer Manage Res (2020) 12:731-41. doi: 10.2147/ cmar.S234618

32. Stanton SE, Disis ML. Clinical Significance of Tumor-Infiltrating Lymphocytes in Breast Cancer. J Immunother Cancer (2016) 4:59. doi: 10.1186/s40425-016-0165-6
33. Liu F, Zeng G, Zhou S, He X, Sun N, Zhu X, et al. Blocking Tim-3 or/and PD-1 Reverses Dysfunction of Tumor-Infiltrating Lymphocytes in HBV-Related Hepatocellular Carcinoma. Bull du Cancer (2018) 105:493-501. doi: 10.1016/ j.bulcan.2018.01.018

34. Mizuno R, Kawada K, Itatani Y, Ogawa R, Kiyasu Y, Sakai Y, et al. The Role of Tumor-Associated Neutrophils in Colorectal Cancer. Int J Mol Sci (2019) 20:529. doi: 10.3390/ijms20030529

35. Lorente L. New Prognostic Biomarkers of Mortality in Patients Undergoing Liver Transplantation for Hepatocellular Carcinoma. World J Gastroenterol (2018) 24:4230-42. doi: 10.3748/wjg.v24.i37.4230

36. Lee KH, Lee CH, Jeong J, Jang AH, Yoo CG. Neutrophil Elastase Differentially Regulates Interleukin 8 (IL-8) and Vascular Endothelial Growth Factor (VEGF) Production by Cigarette Smoke Extract. J Biol Chem (2015) 290:28438-45. doi: 10.1074/jbc.M115.663567

37. Bausch D, Pausch T, Krauss T, Hopt UT, Fernandez-del-Castillo C, Warshaw AL, et al. Neutrophil Granulocyte Derived MMP-9 Is a VEGF Independent Functional Component of the Angiogenic Switch in Pancreatic Ductal Adenocarcinoma. Angiogenesis (2011) 14:235-43. doi: 10.1007/s10456-011-9207-3

38. Kurtagic E, Jedrychowski MP, Nugent MA. Neutrophil Elastase Cleaves VEGF to Generate a VEGF Fragment With Altered Activity. Am J Physiol Lung Cell Mol Physiol (2009) 296:L534-546. doi: 10.1152/ajplung.90505.2008

39. Petrie HT, Klassen LW, Kay HD. Inhibition of Human Cytotoxic T Lymphocyte Activity In Vitro by Autologous Peripheral Blood Granulocytes. J Immunol (Baltimore Md.: 1950) (1985) 134:230-4.

40. Ari A, Gunver F. Comparison of Neutrophil-Lymphocyte Ratio and PlateletLymphocyte Ratio in Patients With Thyroiditis and Papillary Tumors. J Int Med Res (2019) 47:2077-83. doi: 10.1177/0300060519838392

41. Inamoto S, Kawada K, Okamura R, Hida K, Sakai Y. Prognostic Impact of the Combination of Neutrophil-to-Lymphocyte Ratio and Glasgow Prognostic Score in Colorectal Cancer: A Retrospective Cohort Study. Int J Colorectal Dis (2019) 34:1303-15. doi: 10.1007/s00384-019-03316-Z

42. Chen Z, Zhao G, Chen F, Xia J, Jiang L. The Prognostic Significance of the Neutrophil-to-Lymphocyte Ratio and the Platelet-to-Lymphocyte Ratio in Giant Cell Tumor of the Extremities. BMC Cancer (2019) 19:329. doi: 10.1186/s12885-019-5511-x

43. Robinson AV, Keeble C, Lo MCI, Thornton O, Peach H, Moncrieff MDS, et al. The Neutrophil-Lymphocyte Ratio and Locoregional Melanoma: A Multicentre Cohort Study. Cancer Immunol Immunother: CII (2020) 69:559-68. doi: 10.1007/s00262-019-02478-7

44. Zhan H, Ma JY, Jian QC. Prognostic Significance of Pretreatment Neutrophilto-Lymphocyte Ratio in Melanoma Patients: A Meta-Analysis. Clin Chim Acta (2018) 484:136-40. doi: 10.1016/j.cca.2018.05.055

45. Li H, Wang JJ, Zhang M, Ren B, Li JX, Xu L, et al. Prognostic Significance of Systemic Immune-Inflammation Index in Patients With Intrahepatic Cholangiocarcinoma Undergoing Hepatic Resection. World J Gastrointestinal Oncol (2020) 12:467-82. doi: 10.4251/wjgo.v12.i4.467

46. Wang Y, Li Y, Chen P, Xu W, Wu Y, Che G, et al. Prognostic Value of the Pretreatment Systemic Immune-Inflammation Index (SII) in Patients With Non-Small Cell Lung Cancer: A Meta-Analysis. Ann Trans Med (2019) 7:433. doi: $10.21037 /$ atm.2019.08.116

47. Gorgel SN, Akin Y, Koc EM, Kose O, Ozcan S, Yilmaz Y, et al. Retrospective Study of Systemic Immune-Inflammation Index in Muscle Invasive Bladder Cancer: Initial Results of Single Centre. Int Urol Nephrol (2020) 52:469-73. doi: 10.1007/s11255-019-02325-9

48. Chen L, Kong X, Wang Z, Wang X, Fang Y, Wang J, et al. Pre-Treatment Systemic Immune-Inflammation Index Is a Useful Prognostic Indicator in Patients With Breast Cancer Undergoing Neoadjuvant Chemotherapy. J Cell Mol Med (2020) 24:2993-3021. doi: 10.1111/jcmm.14934

49. Zhang Y, Sun Y, Zhang Q. Prognostic Value of the Systemic ImmuneInflammation Index in Patients With Breast Cancer: A Meta-Analysis. Cancer Cell Int (2020) 20:224. doi: 10.1186/s12935-020-01308-6

Conflict of Interest: The authors declare that the research was conducted in the absence of any commercial or financial relationships that could be construed as a potential conflict of interest.

Publisher's Note: All claims expressed in this article are solely those of the authors and do not necessarily represent those of their affiliated organizations, or those of the publisher, the editors and the reviewers. Any product that may be evaluated in 
this article, or claim that may be made by its manufacturer, is not guaranteed or endorsed by the publisher.

Copyright $\odot 2021 \mathrm{Li}, \mathrm{Ma}$, Deng, Chen, Liu, Chen and Wu. This is an open-access article distributed under the terms of the Creative Commons Attribution License
(CC BY). The use, distribution or reproduction in other forums is permitted, provided the original author(s) and the copyright owner(s) are credited and that the original publication in this journal is cited, in accordance with accepted academic practice. No use, distribution or reproduction is permitted which does not comply with these terms. 